\title{
MEDIA INFORMASI E-COMPLAINT KRIMINAL PADA DAERAH INDRAMAYU BERBASIS SMS GATEWAY
}

\author{
Willy Permana Putra ${ }^{1}$, Luthfi Khamdani ${ }^{2}$ \\ ${ }^{1,2}$ Program Studi Teknik Informatika Politeknik Negeri Indramayu \\ Jl. Lohbener Lama Nomor 8 Lohbener Indramayu. \\ ${ }^{1}$ E-mail : willy@polindra.ac.id, ${ }^{2}$ E-mail : luthfi.khamdani@gmail.com
}

\begin{abstract}
Abstrak
Pada saat masyarakat ingin mengadukan atau komplain tentang adanya tindak kriminalitas kepada pihak kepolisian sering mendapatkan kesulitan dikarenakan untuk mendapatkan nomor kontak dari masing-masing polsek dari daerah yang sedang terjadi kriminal. Aplikasi media informasi e-complaint kriminal ini memudahkan untuk masyarakat khususnya diwilayah Indramayu untuk melakukan pengaduan dari setiap kriminal yang pada daerahnya masingmasing dengan cepat agar dari pihak kepolisian dapat memproses lebih lanjut dan dapat mempersempit jalur kriminalitas pada wilayah indramayu. Dengan menyediakan aplikasi ini masyarakat dapat mengadu kepada kepolisian kapanpun dan dimanapun. Sistem ini dikembangkan dengan menggunakan aplikasi gammu, PHP, dan database server MySQL. Pengujian sistem dilakukan diantaranya user melakukan sms dengan format pengaduan. Dari hasil pengujian sistem dimana pembangunan komponen-komponen pokok sebuah sistem. Dari sistem cukup mudah digunakan dan sudah memenuhi dari user requirement. Selain itu aplikasi ini dapat membantu masyarakat untuk mendapatkan informasi ataupun mengadukan kejadian kriminal dimanapun dan kapanpun secara real-time.

Hasil penelitian menyimpulkan bahwa aplikasi media informasi e-complaint ini sangat membantu masyarakat dalam mendapatkan informasi dan pengaduan.
\end{abstract}

Kata Kunci : media informasi e-complaint kriminal, Informasi, PengaduanPHP, MySQL, Gammu.

\section{PENDAHULUAN}

Informasi merupakan hal yang mutlak yang dibutuhkan oleh mayarakat luas. Pada masa sekarang informasi bukan lagi merupakan produk pelengkap melainkan kebutuhan utama. Komunikasi dapat diartikan sebagai suatu cara penyampaian informasi, gagasan serta juga cara menyampaikan kepada pihak lain. Telepon selular adalah perangkat telekomunikasi elektronik yang mempunyai kemampuan dasar yang sama dengan telepon, SMS (Short Message Services) dan bisa untuk bermain internet.

Short Message Service (SMS) merupakan layanan yang banyak diaplikasikan pada sistem komunikasi tanpa kabel (nirkabel), memungkinkan dilakukannya pengiriman pesan dalam bentuk alphanumeric antar terminal pelanggan atau antar terminal pelanggan dengan sistem eksternal seperti e-mail, paging, voice mail dan lain-lain.

SMS pertama kali muncul di belahan Eropa pada tahun 1991 bersama sebuah teknologi komunikasi wireless yang saat ini cukup banyak penggunanya, yaitu Global Sistem for 
Mobile Communication (GSM). Dipercaya bahwa pesan pertama yang dikirim menggunakan SMS dialakukan pada bulan Desember 1992, dikirim dari sebuah Personal Computer (PC) ke telepon dalam jaringan GSM milik Vodafone Inggris. Perkembagan kemudian merambah ke benua Amerika, dipelopori oleh beberapa operator komunikasi bergerak berbasis digital seperti Bell Sputh Mobility, PrimeCo, Nextel, dan beberapa operator lain. Teknologi digital yang digunakan sangat bervariasi dari yang berbasis GSM, Time Division Multiple Access (TDMA), hingga Code Division Multiple Access (CDMA).

Seiring dengan kemajuan perkembangan tersebut, memungkinkan munculnya aplikasiaplikasi terbaru yang bisa membantu dalam hal apapun terutama dalam hal menyampaikan permasalahan yang ada. Saat ini hampir semua orang dapat melakukan pengiriman informasi secara effisien, dengan memanfaatkan teknologi ini tentusaja memudahkan dalam hal penyampaian informasi. Namun melihat perkembangan yang begitu cepat tentunya belum sepenuhnya di manfaatkan oleh pemerintah salah satunya adalah media pelayanan dalam hal ini pengaduan.

Di pemerintahan Indramayu sendiri pelayanan yang sudah ada bersifat manual dalam artian harus datang dan melaporkan permasalahannya kemudia dan tidak ada tindak lanjut yang jelas, sehingga masyarakat umumnya kurang puas terhadap pengaduan yang ada.

Dalam hal ini kebutuhan informasi dan pengaduan yang tepat sasaran, dimanapun dan kapanpun merupakan hal yang seharusnya di tingkatkan maka dengan adanya SMS Gateway dalam proses penyampaian informasi dan pengaduan kepada kepolisian wilayah Indramayu harus di terapkan. Pemanfaatan ini tanpa harus menggunakan komputer dan menggunakan internet, cukup dengan menggunakan ponsel masyarakat dapat menyampaikan maupun mengadukan informasi kejadian kepada pihak kepolisian dengan mudah dan cepat.

\section{KAJIAN PUSTAKA}

Ellul (dalam Miarso, 2004) seorang sosiolog Perancis, mengartikan teknologi sebagai keseluruhan metode yang secara rasional mengarah dan memiliki ciri efisiensi dalam setiap kegiatan manusia. Dalam buku yang sama, Gary J. Anglin mendefinisikan teknologi sebagai penerapan ilmu-ilmu perilaku dan alam serta pengetahuan lain secara bersistem dan menyistem, untuk memecahkan berbagai masalah yang dihadapi manusia. Teknologi yang tepat guna adalah teknologi yang sesuai dengan budaya masyarakat yang bersangkutan. Toga Aldila Cinderatama melakukan penelitian tentang basis data terdistribusi untuk apliasi kependudukan berbasis web menyatakan bahwa implementasi database terdistribusi pada suatu sistem aplikasi dapat menghasilkan performansi yang baik menyangkut ketersediaan data. Adanya replikasi database yang dapat menghasilkan kesamaan posisi data pada beberapa mastersite, maka memungkinkan adanya pembagian beban dalam pengaksesan kerja server, sehingga kegagalan pengaksesan data dapat diminimalisasikan.

Era teknologi informasi ditandai dengan kemudahan dan kecepatan aliran informasi dari satu komunitas ke yang lainnya. Salah satu produk teknologi adalah telekomunikasi menggunakan perangkat telepon atau telepon seluler. Didalamnya terdapat sebuah metode komunikasi yang dinamakan Short Message Service (SMS) yaitu sebuah konsep pengiriman informasi berbasis teks (Dewanto, 2007).

Seiring dengan perkembangannya, SMS tidak hanya digunakan untuk mengirimkan atau bertukar informasi antara dua orang yang saling mengenal atau membutuhkan, SMS sudah mulai digunakan untuk berhubungan antara seseorang dengan sistem sesuai dengan kebutuhan (Adil, 2009)[8].

Pengaduan masyarakat merupakan bentuk penerapan dari pengawasan masyarakat yang disampaikan oleh masyarakat kepada aparatur pemerintah baik instansi maupun dinas pemerintah terkait berupa sumbang pikr suara, gagasan, keluhan, pengaduan yang bersifat membangun. Pengaduan adalah pernyataan secara lisan atau tulis atau ketidak puasan seseorang terhadap pelayanan yang diberikan oleh sistem pelayanan (Anwar Hadi, 2000) 


\section{METODE PENELITIAN}

Metodologi penelitian adalah cara teknik untuk pelaksanaan penelitian yang sedang dilaksanakan penulis. Metodologi ini amat perlu dirumuskan dengan jelas, mengingat bahwa suatu penilitian tanpa menempuh cara atau prosedur yang tepat dan benar maka hasilnya tidak akan akurat seperti apa yang diharapkan.

Metodologi adalah cara berfikir dan berbuat yang dipersiapkan dengan sebaik-baiknya untuk mengadakan sebuah proses baik itu penelitian ataupun lainnya.

Sedangkan penelitian adalah suatu kegiatan pencarian, penyelidikan, dan percobaan secara ilmiah dalam suatu bidang tertentu untuk mendapatkan fakta-fakta atau prinsipprinsip baru bertujuan untuk mendapatkan pengertian baru daan menaikkan tingkat ilmu secara teknologi.

Dari pengertian ini dapat dimengerti bahwa metodelogi penelitian merupakan rangkain atau tahapan kerja yang harus ditempuh untuk dijadikan landasan melaksanakan kegiatan penelitian, yakni untuk memperoleh suatu jawaban atau suatu kesimpulan suatu objek yang diteliti. Adapaun gambaran flowchart tahapan kerja sesuai metodelogi penelitian.

\subsection{Studi Pustaka}

Merupakan pengumpulan data yang dilakukan dengan mencari, membaca dan mengumpulkan dokumen-dokumen sebagai referensi seperti buku, artikel dan literaturliteratur dan browsing di internet yang berhubungan dengan metode informasi ecomplaint kriminal.

\subsection{Observasi}

Merupakan pengumpulan data yang dilakukan dengan melihat langsung ke suatu pusat data (data center) di suatu organisasi yang telah menerapkan sistem data center terpadu.

\subsection{Jalannya Penelitian}

Metode yang dilakukan dengan membuat simulasi suatu sistem e-complaint pada daerah Indramayu, untuk merepresentasikan keadaan yang terjadi sesungguhnya di infrastruktur pada daerah tersebut. Di pengujian e-complaint ini dibutuhkan handphone yang digunakan oleh masyarakat untuk pengaduan atau mendapatkan informasi, modem untuk mengirimkan tanggapan atau informasi dari admin kepolisian dan database server digunakan untuk menyimpan nomor telepon maupun informasi.

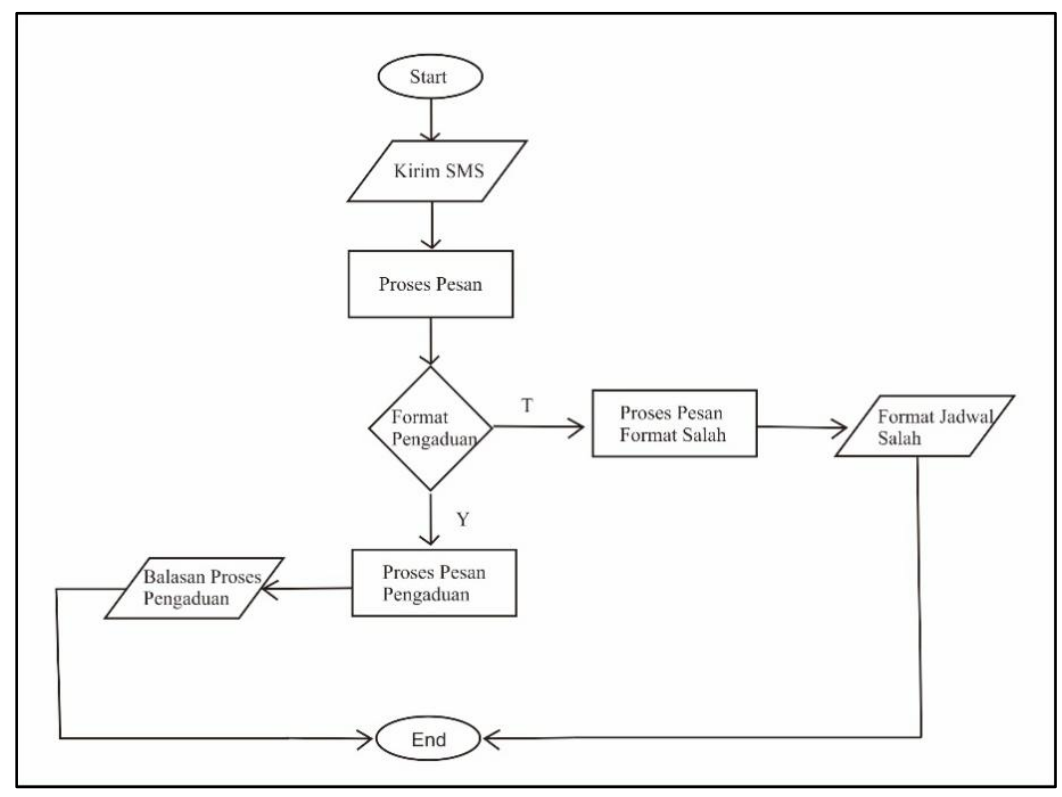

Gambar 2.Flow chart jalannya Sistem

Berdasarkan gambar 2, penelitian ini akan dilakukan dengan tahapan sebagai berikut: 
1) Masyarakat mengirimkan pesan dengan format komplain, jika formatnya sesuai dengan ketentuan maka akan ada balasan komplain anda akan segera diproses.

2) Dan jika format komplain salah maka akan ada balasan maaf format salah

3) Jika pesan sudah terkirim ke database server maka server akan membalas pesan ke sepengirin dan akan meneruskan pesan tersebut ke admin polsek/kepolisian.

\section{HASIL DAN PEMBAHASAN}

4.1. Implementasi Media Informasi E-Complaint Kriminal

Implementasi media informasi e-complaint kriminal ini menggunakan aplikasi pendukung SMS (Short Message Services). Tahapan yang dilakukan untuk mengimplementasikan media informasi e-complaint kriminal tersebut:

\subsubsection{Konfigurasi Aplikasi Gammu}

Pada pembuatan aplikasi SMS Gateway ini membutuhkan konfigurasi pada aplikasi gammu agar aplikasi tersebut dapat berjalan dengan baik.

1. Ekstrak file gammu yang sudah didownload pada directory $C: \mid x a m p p \backslash h t d o c s ~ d a n$ beri nama foldernya gammu atau sesuai keinginan.

2. Setelah itu copy file gammurc dan smsdrc dari directory $\mathrm{C}: \mid x a m p p \backslash h t d o c s \backslash g a m m u \backslash$ share $\backslash$ doc $\backslash$ gammulexamples\config $\quad$ ke directory

C: xampp \htdocs \gammulbin.

3. Ubah isi file dari gammurc dan smsdrc seperti dibawah ini :

[ gammurc ]

device = com3: // port pada modem

connection = at // connection yang sudah disediakan gammu

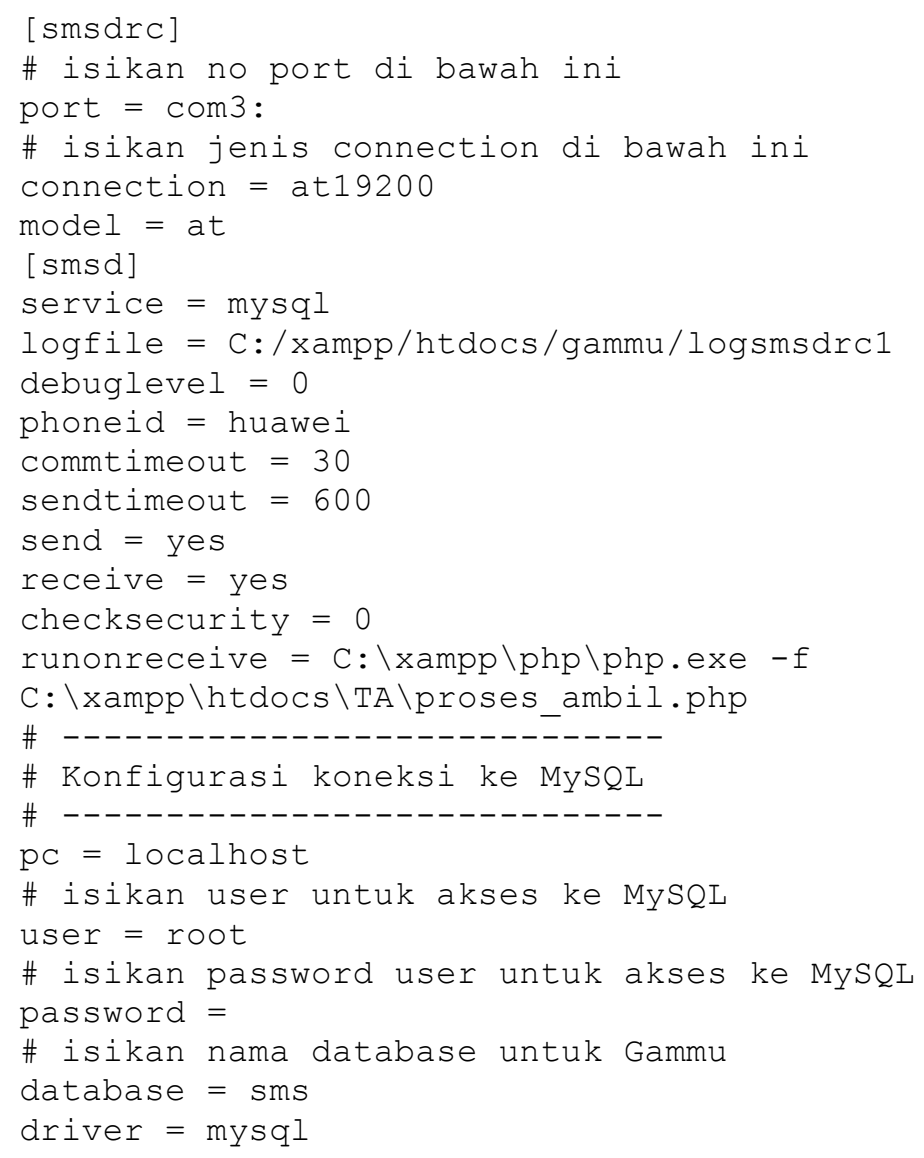


4. Buat database sesuai yang sudah dituliskan pada file smsdrc dan import database default dari gammu pada directory gammu yang sudah disimpan misalkan Gammulshareldoc|gammulexamples\sq1/mysql.sql, contoh bisa dilihat pada gambar dibawah ini :

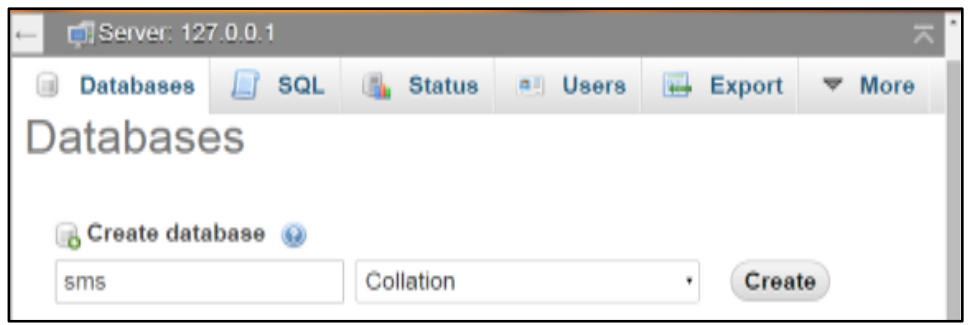

Gambar 3. Pembuatan Database

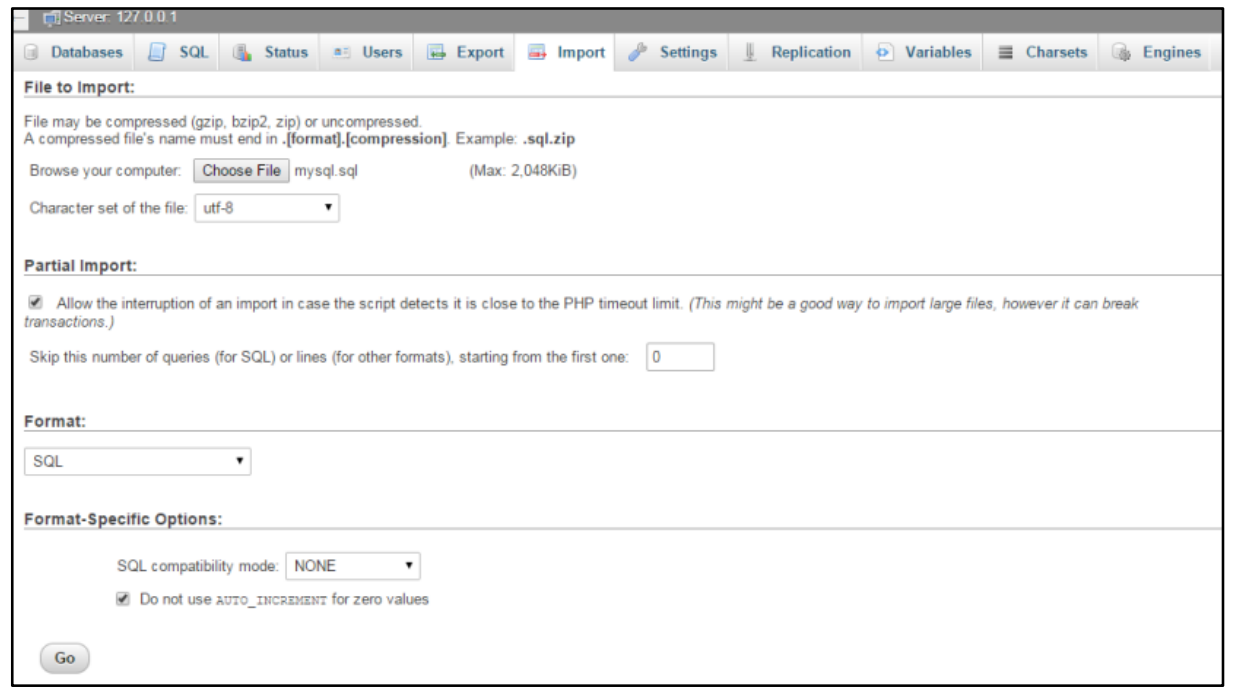

Gambar 4. Import Database

\subsection{Pengujian Replikasi Basis Data dengan MySQL Server}

Pengujian merupakan bagian yang penting dalam siklus pengembangan perangkat lunak pengujian dilakukan untuk menjamin kualitas dan juga mengetahui kelemahan dari perangkat lunak yang dibangun memiliki kualitas yang handal, yaitu mampu mempresentasikan kajian pokok dari spesifikasi, analisis, perancangan dan pengkodean dari perangkat lunak itu sendiri.

\subsubsection{Pengujian Pesan Format Komplain}

Pesan ini berfungsi untuk masyarakat dalam pengaduan kepada pihak kepolisian terhadap tindak kriminalitas yang terdapat pada wilayahnya, dengan cara ketik KOMPLAIN (spasi) PENGADUAN ANDA. Contoh pesan terlihat pada gambar dibawah ini : 

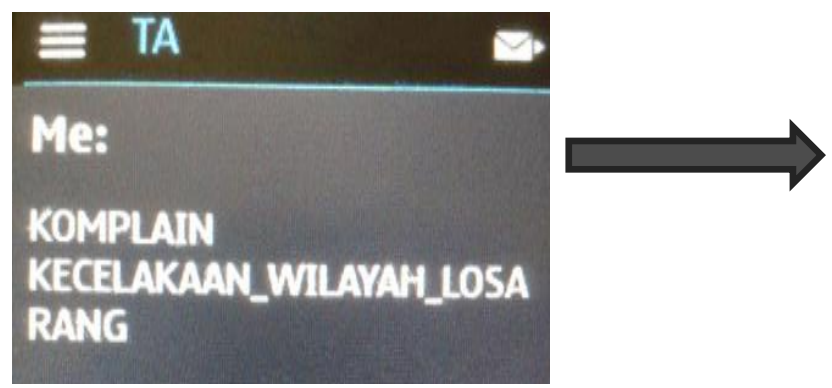

Gambar 5. (a)

Contoh Pesan Format Komplain (b) Balasan Komplain

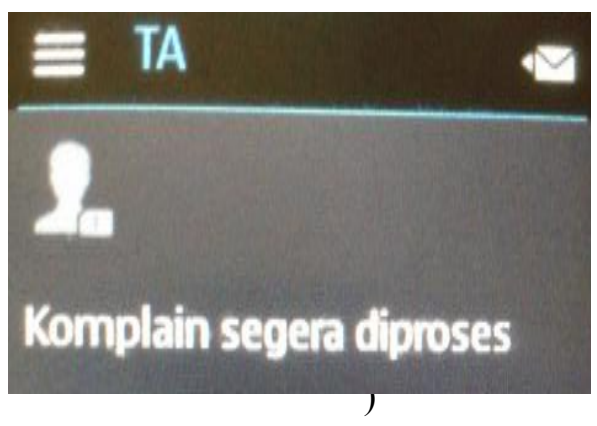

\subsubsection{Pengujian Pesan Format Salah}

Pesan ini berfungsi untuk memberitahukan kepada masyarakat bahwa pesan yang dikirimkan formatnya salah. Contoh pesan terlihat pada gambar dibawah ini :

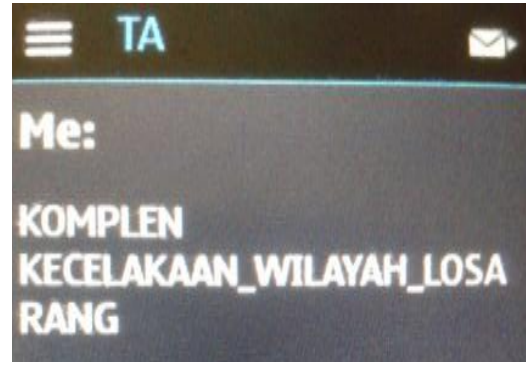

(a)

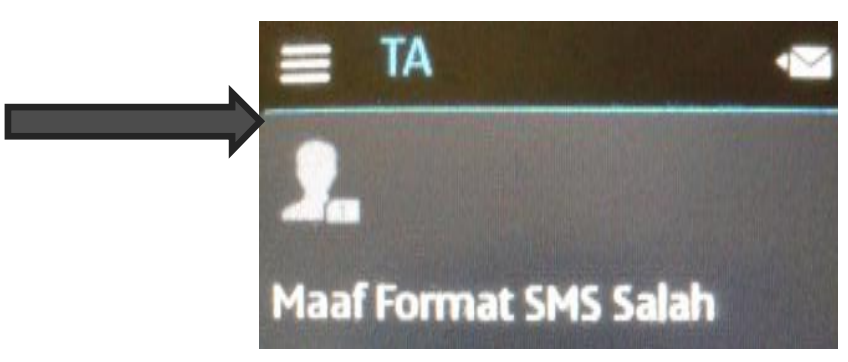

(b)

Gambar 5. (a) Contoh Pesan Format Salah (b) Balasan Format Salah

\section{KESIMPULAN}

Kesimpulan yang didapat setelah menganalisa, mengembangkan dan melakukukan pengujian aplikasi yang dihasilkan adalah :

1. Aplikasi e-complaint kriminal berbasis sms gateway ini menyediakan fasilitas untuk memberikan informasi atau pengaduan kepada pihak kepolisian dari masyarakat.

2. Aplikasi ini dapat digunakan dengan mudah dan cepat karena bisa dilakukan kapanpun dan dimanapun. 
3. Aplikasi ini tidak membutuhkan internet hanya menggunakan fasilitas telepon seluler yang sederhana.

\section{DAFTAR PUSTAKA}

[1] Mical Cihar. 2007. Gammu Phone Database. http://wammu.eu. Diakses pada tanggal 9 Juni 2015.

[2] Mical Cihar. 2007. SMSD Configuration Files. http://wammu.eu. Diakses pada tanggal 2 Juni 2015.

[3] Rosihanari. 2009. Script Auto Reply SMS Gateway dengan PHP. http://blog.rosihanari.net. Diakses pada tanggal 3 Juni 2015.

[4] Wahana Komputer. 2014. Mudah Membuat Aplikasi SMS Gateway dengan CodeIgniter. Jakarta: PT Elex Media Komputindo. 